\title{
Comparison of the Electrocardiographic Changes Induced by Dipyridamole Infusion and Treadmill Exercise in Patients with Coronary Artery Disease
}

\author{
Sukehiko Kawashima, M.D., Isao Kubota, M.D., Kozue Ikeda, M.D., \\ Kai Tsurki, M.D., and Shoji Yasur, M.D.
}

\section{SUMMARY}

To determine whether dipyridamole infusion can be used as an alternative method to physical exercise, 87 lead body surface mapping was performed to compare the distribution patterns of ST-segment depression after $0.568 \mathrm{mg} / \mathrm{kg} / 4 \mathrm{~min}$ dipyridamole infusion (D) and after submaximal treadmill exercise (T) in 21 patients with coronary artery disease. Significant ST-segment depression $(\geq 0.05 \mathrm{mV}$ ) was observed in 19 patients after $\mathrm{D}$ and in 18 after $T$. After $D$ and $T$, each patient showed a similar distribution pattern of ST-segment depression. There were no significant differences in the number of leads which showed ST-segment

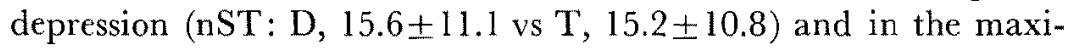
mal value of ST-segment depression (STmax: D, $-0.24 \pm 0.16$ vs $\mathrm{T},-0.20 \pm 0.13 \mathrm{mV}$ ). Good correlations were observed in $\mathrm{nST}$ $(r=0.84)$ and in STmax $(r=0.87)$ between $D$ and $T$. The increase in mean pressure-rate product after $\mathrm{T}$ was $89 \%$, while the increase after $\mathrm{D}$ was only $22 \%$. Our results suggest that this pharmacologic test to induce myocardial ischemia may be useful in the evaluation of coronary artery disease in patients who are physically unable to perform adequate exercise.

\section{Additional Indexing Words:}

Dipyridamole test Coronary artery discase Body surface mapping

\footnotetext{
$\mathrm{R}^{\mathrm{r}}$ EGENTLY, intravenous infusion of dipyridamole has been proposed as an alternative method to physical exercise for the detection of coronary artery disease by myocardial perfusion imaging with thallium-201.1)-9) It is presumed that the powerful coronary vasodilatory effect of this drug will

From the First Department of Internal Medicine, Yamagata University School of Medicine, Yamagata.

Address for reprint: Sukehiko Kawashima, M.D., First Department of Internal Medicine, Yamagata University School of Medicine, Zao-Iida, Yamagata 990-23, Japan.

Received for publication August 26, 1985.

Manuscript revised January 17, 1986.
} 
greatly increase myocardial blood flow in those regions served by normal coronary vessels but not in regions served by diseased vessels. Experimental and clinical studies have shown that in the presence of coronary artery disease dipyridamole may cause a nonhomogeneous distribution of coronary blood flow and produce perfusion defects in regions supplied by diseased vessels. ${ }^{10)-17)}$ Although intravenous infusion of dipyridamole may also induce ischemic STsegment shift, ${ }^{2,3), 5)-9), 15), 18,, 19}$ there are few data on the clinical significance of these electrocardiographic changes in comparison with the number of studies with myocardial perfusion imaging. This pharmacologic test may be uscful in the evaluation of coronary artery disease, especially in patients who are physically unable to perform adequate exercise.

The purpose of this study was to compare the electrocardiographic changes induced by treadmill exercise and dipyridamole infusion in patients with coronary artery disease by means of the body surface mapping technique in order to determine the clinical usefulness of dipyridamole electrocardiography as an alternative test to exercise electrocardiography for the diagnosis of coronary artery disease.

\section{Materials AND Methods}

\section{Study population}

The subjects were 21 patients ( 18 men and 3 women) with known coronary artery disease. They were aged 48 to 73 (average 61) years. At coronary arteriography, all patients were found to have coronary narrowing of $\geq 70 \%$ in luminar diameter in one or more coronary arteries. None had a history of previous myocardial infarction with diagnostic enzyme and/or electrocardiographic changes. Patients with electrocardiographic evidence of intraventricular conduction disturbances or ST-segment changes at rest were not included. Three of the patients had one vessel disease, 6 had two and 12 had three vessel and/or left main trunk disease. Informed consent was obtained from all patients.

\section{Treadmill exercise test}

Submaximal treadmill exercise tests were performed according to the Brucc protocol. Eighty-seven lead electrocardiographic mapping was performed with the patient in the supine position before and $1.5 \mathrm{~min}$ after the cessation of exercise, using a technique previously described. ${ }^{20)-22)}$

Dipyridamole infusion test

With the patient in the supine position, dipyridamole was infused 
intravenously at a rate of $0.142 \mathrm{mg} / \mathrm{kg}$ per minute for $4 \mathrm{~min}$ (total dose of $0.568 \mathrm{mg} / \mathrm{kg}$ ). ${ }^{\text {3) }}$ Continuous electrocardiographic monitoring was performed using a CM-5 lead ECG before, during and for at least 20 min after the beginning of infusion, and blood pressure and heart rate were recorded at $1 \mathrm{~min}$ intervals throughout the test. Eighty-seven lead mapping was performed just before and at $5,10,15$ and $20 \mathrm{~min}$ after the beginning of the infusion. Aminophylline (125-250 mg), which specifically blocks the vasodilating action of dipyridamole, ${ }^{23)}$ was intravenously administered if the patient experienced moderate or severe angina with ischemic ST-segment depression.

All subjects underwent both the treadmill test and the dipyridamole test within 2 weeks before or after cardiac catheterization and coronary arteriography. All medications were withheld for at least 24 hours before the tests.

\section{Body surface mapping}

Body surface mapping was performed with the use of the HPM-5100 system (Chunichi Denshi Co., Nagoya). ${ }^{24)}$ Eighty-seven electrodes were placed over the torso, 59 leads on the anterior chest and 28 on the back. ${ }^{20)-22}$ ) The data were recorded in digital format, using Wilson's central terminal as a reference, at a rate of 250 samples/sec. Data sampling was always done at the resting expiratory level in the supine position. Each lead of the ECG was analyzed for exercise- or dipyridamole-induced significant ST-segment depression which was defined as $0.05 \mathrm{mV}$ or greater horizontal or downsloping ST-segment depression below the baseline, lasting $0.08 \mathrm{sec}$. STsegment voltage was measured at $0.04 \mathrm{sec}$ from the $\mathrm{J}$ point. In this study we used the number of lead points which showed ST-segment depression (nST) and the maximal value of ST-segment depression (STmax) as indices of the extent and severity of exercise- or dipyridamole-induced ST-segment depression.

\section{Comparison of the two tests}

In the dipyridamole test, the recording which developed the greatest value of STmax after infusion was chosen for further analysis. The indices used to compare the electrocardiographic changes in the two tests were nST, STmax and the lead point which developed STmax (site of STmax). After intervention, heart rate and blood pressure at the end of exercise in the treadmill tests and those at the time of the recording of the mapping data in the dipyridamole tests were compared. When ischemic ST-segment depression was not induced by dipyridamole, the highest heart rate after infusion and the blood pressure at the same time were used. Thus, the hemodynamic 
parameters used for comparison both before and after intervention were obtained with the patients standing in the treadmill tests and with the patients in the supine position in the dipyridamole tests.

\section{Statistical analysis}

The correlation between $\mathrm{nST}$ (STmax) in the treadmill test and $\mathrm{nST}$ (ST max) in the dipyridamole test was assessed using the least-squares method of linear regression analysis to determine the correlation coefficient. Quantitative data were expressed as mean $\pm \mathrm{SD}$. Statistical comparisons were done by the paired t-test; $\mathrm{p}<0.05$ was considered significant.

\section{RESULts}

Coronary arteriographic findings and the results of the treadmill and dipyridamole tests are shown in Table I. Of the 21 patients, 18 developed

Table 1. Coronary Arteriographic Findings and Electrocardiographic Changes Following Treadmill Exercise and Dipyridamole Infusion

\begin{tabular}{|c|c|c|c|c|c|c|c|c|c|c|c|c|}
\hline \multirow{2}{*}{ Case } & \multirow{2}{*}{$\begin{array}{c}\text { Age } \\
\text { (year) }\end{array}$} & \multirow{2}{*}{ Sex } & \multicolumn{4}{|c|}{ Stenosis } & \multicolumn{2}{|c|}{$\mathrm{nST}$} & \multicolumn{2}{|c|}{ STmax $(\mathrm{mV})$} & \multicolumn{2}{|c|}{ Site of STmax } \\
\hline & & & I.MT & RCA & LAD & LCX & $\mathbf{T}$ & $\mathrm{D}$ & $\mathrm{T}$ & $\mathrm{D}$ & $\mathrm{T}$ & $\mathrm{D}$ \\
\hline 1 & 60 & $\mathrm{M}$ & + & + & + & + & 17 & 23 & -0.14 & -0.26 & G4 & G4 \\
\hline 2 & 71 & $\mathbf{F}$ & + & - & + & + & 26 & 26 & -0.27 & -0.28 & G4 & $\mathrm{G} 4$ \\
\hline 3 & 63 & $\mathbf{M}$ & - & + & + & + & 11 & 11 & -0.08 & -0.11 & $\mathrm{H} 4$ & $\mathrm{H} 4$ \\
\hline 4 & 66 & $\mathbf{F}$ & - & + & + & + & 9 & 5 & -0.14 & -0.07 & H3 & H3 \\
\hline 5 & 62 & $\mathbf{F}$ & - & + & + & + & 30 & 28 & -0.46 & -0.47 & G4 & $\mathrm{G} 4$ \\
\hline 6 & 65 & $\mathbf{M}$ & - & + & + & + & 16 & 22 & -0.11 & -0.16 & G4 & $\mathrm{G} 4$ \\
\hline 7 & 51 & $\mathbf{M}$ & - & + & + & + & 1 & 4 & -0.07 & -0.09 & 13 & 13 \\
\hline 8 & 48 & $\mathbf{M}$ & - & + & + & + & 28 & 26 & -0.23 & -0.31 & G4 & $\mathrm{G} 4$ \\
\hline 9 & 60 & $\mathbf{M}$ & - & + & + & + & 0 & 6 & - & -0.11 & - & $\mathrm{H} 3$ \\
\hline 10 & 73 & $\mathbf{M}$ & - & + & + & + & 31 & 36 & -0.50 & -0.72 & H4 & $\mathrm{G} 4$ \\
\hline 11 & 68 & $\mathrm{~F}$ & - & + & + & + & 24 & 28 & -0.28 & -0.32 & G4 & $\mathrm{G} 4$ \\
\hline 12 & 70 & $\mathrm{M}$ & - & + & + & + & 0 & 0 & - & - & - & - \\
\hline 13 & 55 & $\mathrm{M}$ & - & + & + & - & 28 & 31 & -0.26 & -0.30 & H4 & $\mathrm{H} 4$ \\
\hline 14 & 57 & $\mathbf{M}$ & - & + & + & - & 10 & 6 & -0.15 & -0.13 & H4 & $\mathrm{H} 4$ \\
\hline 15 & 58 & $\mathbf{M}$ & - & + & + & - & 0 & 0 & - & - & - & - \\
\hline 16 & 51 & $\mathbf{M}$ & - & + & - & + & 18 & 7 & -0.10 & -0.10 & H4 & $\mathrm{H} 4$ \\
\hline 17 & 59 & $\mathbf{M}$ & - & - & + & + & 6 & 12 & -0.10 & -0.18 & $\mathrm{H} 4$ & $\mathrm{H} 4$ \\
\hline 18 & 61 & $\mathbf{M}$ & - & + & + & - & 26 & 12 & -0.18 & -0.07 & G3 & H3 \\
\hline 19 & 63 & $\mathrm{M}$ & - & - & + & - & 11 & 24 & -0.15 & -0.35 & $\mathrm{H} 4$ & $\mathrm{G} 4$ \\
\hline 20 & 54 & $\mathbf{M}$ & - & - & + & - & 21 & 13 & -0.31 & -0.25 & G4 & $\mathrm{G} 4$ \\
\hline 21 & 70 & $\mathbf{M}$ & - & - & - & + & 6 & 8 & -0.06 & -0.10 & $\mathrm{H} 4$ & $\mathrm{H} 4$ \\
\hline
\end{tabular}

Abbreviations: $\mathrm{D}=$ dipyridamole infusion; $\mathrm{LAD}=$ left antrior descending artery; $\mathrm{LCX}=\mathrm{left}$ circumflex artery; $\mathbf{L M T}=$ left main trunk; $\mathbf{R C A}=$ right coronary artey; $\mathrm{T}=$ treadmill exercise. 
significant ST-segment depression in at least one lead both after treadmill exercise and after dipyridamole infusion. One patient had ST-segment depression only after dipyridamole infusion (Case 9). Two patients did not develop ST-segment depression in either test (Cases 12 and 15). During treadmill exercise, all 18 patients with ST-segment depression experienced angina. Of the 19 patients with ST-segment depression during the dipyridamole test, 14 had maximal values of STmax at $10 \mathrm{~min}$ and 5 at $15 \mathrm{~min}$ after the beginning of infusion. All 19 patients experienced moderate or severe angina after dipyridamole infusion and aminophylline was infused to relieve it in 17 patients.

\section{Representative case}

Fig. 1 shows all ECG waveforms before (A) and at $1.5 \mathrm{~min}$ after (B) treadmill exercise, and $10 \mathrm{~min}$ after the beginning of dipyridamole infusion (C) in 1 patient with three vessel disease (Case 11). The leads which developed significant ST-segment depression after treadmill exercise or dipyridamole infusion are surrounded by a solid line. The arrows indicate the site of STmax. After both treadmill exercise and dipyridamole infusion, the body surface distribution of the ST-segment depression exhibited quite similar patterns; the site of STmax was lead G4 and the area of ST-segment depression was present around the left anterior chest. In the treadmill test nST was 24 and STmax was $-0.28 \mathrm{mV}$, and in the dipyridamole test nST was 28 and STmax was $-0.32 \mathrm{mV}$.

\section{Electrocardiographic changes}

In 18 patients who developed ST-segment depression after both treadmill exercise and dipyridamole infusion, the difference of the site of STmax between the two tests was investigated. The sites of STmax in both tests were always located at limited lead points on the left anterior chest (leads H3, H4, G4 and I3) and were not separated from each other by more than one electrode row (Table I). In $15(83 \%)$ of the 18 patients, the sites of STmax were located at the same position.

There was no significant difference in the value of nST and STmax between the treadmill test and the dipyridamole test (Tables I and II). Relationship between $\mathrm{nST}$ after treadmill exercise and $\mathrm{nST}$ after dipyridamole infusion was investigated for individual patients (Fig. 2). There was a good correlation between them $(r=0.84)$. In 18 patients with significant STsegment depression in both tests, we correlated STmax after treadmill exercise with STmax after dipyridamole infusion for individual patients (Fig. 3). A good correlation was observed $(r=0.87)$. 


\section{A) Control}

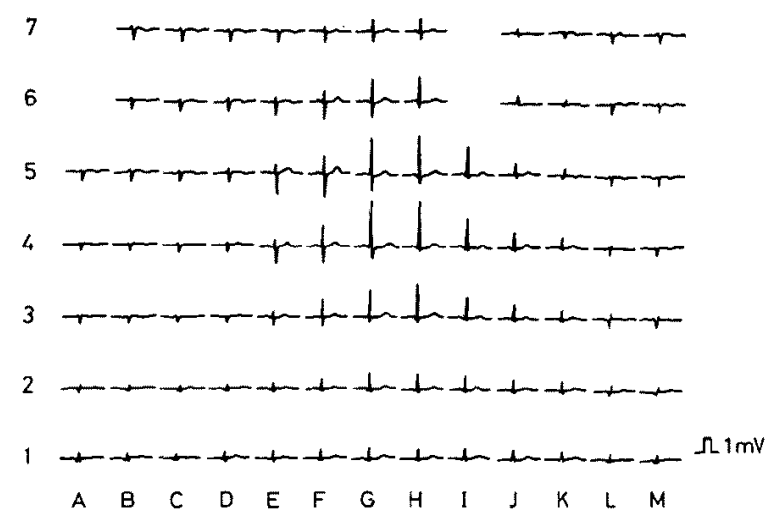

\section{B) after treadmill exercise}

$n S T=24$

$S T \max =-0.28 \mathrm{mV}$

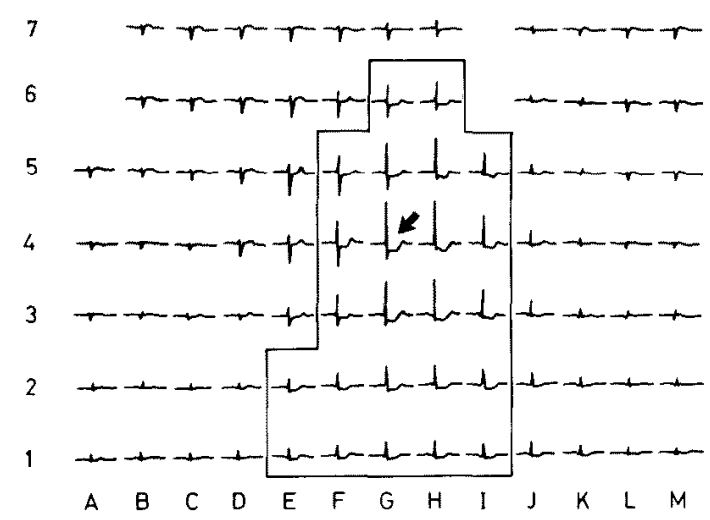

\section{C) after dipyridamole infusion $n S T=28$}

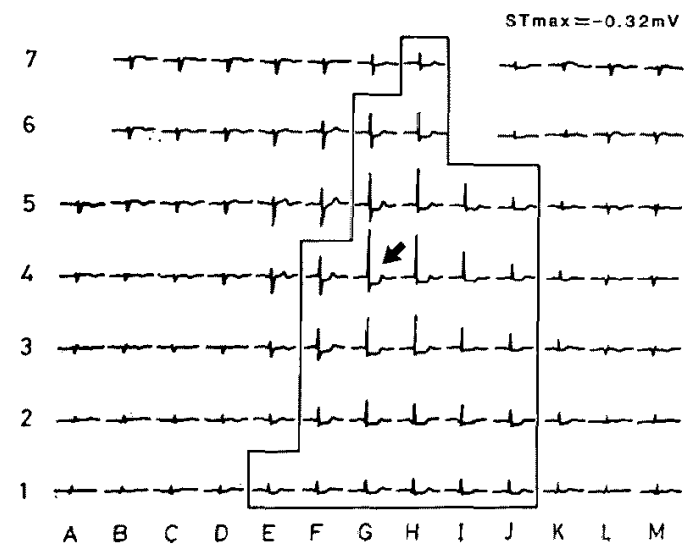

Fig. 1.

All ECG waveforms recorded before (A) and at $1.5 \mathrm{~min}$ after (B) submaximal treadmill exercise and $10 \mathrm{~min}$ after the beginning of dipyridamole infusion (G). The leads which developed STsegment depression are surrounded by a solid line. The arrows indicate the site of STmax. After both treadmill exercise and dipyridamole infusion, the body surface distribution of ST-segment depression exhibited quite similar patterns. 
Table II. Summary of Changes in Electrocardiograms, Heart Rate, Systolic Blood Pressure and Pressure-Rate Product Following Treadmill

Exercise and Dipyridamole Infusion

\begin{tabular}{ll|c|c|c}
\hline & & $\begin{array}{c}\text { Treadmill } \\
(\text { mean } \pm \mathrm{SD})\end{array}$ & $\begin{array}{c}\text { Dipyridamole } \\
\text { (mean } \pm \mathrm{SD})\end{array}$ & Significance \\
\hline $\mathrm{nST}$ & $15.2 \pm 10.8$ & $15.6 \pm 11.1$ & $\mathrm{NS}$ \\
$\mathrm{STmax}(\mathrm{mV})$ & & $-0.20 \pm 0.13$ & $-0.24 \pm 0.16$ & $\mathrm{NS \#}$ \\
$\mathrm{HR}$ (beats/min) & before & $71 \pm 11$ & $65 \pm 10$ & $\mathrm{p}<0.01$ \\
& after & $114 \pm 19 \# \#$ & $79 \pm 13 \# \#$ & $\mathrm{p}<0.01$ \\
$\mathrm{SBP}(\mathrm{mmHg})$ & before & $136 \pm 24$ & $144 \pm 20$ & $\mathrm{NS}$ \\
& after & $163 \pm 22 \# \#$ & $145 \pm 18$ & $\mathrm{p}<0.01$ \\
$\mathrm{PRP}(\times 10 \mathrm{mmHg}$ & before & $98 \pm 23$ & $93 \pm 17$ & $\mathrm{NS}$ \\
beats/min) & after & $185 \pm 42 \# \#$ & $113 \pm 23 \# \#$ & $\mathrm{p}<0.01$
\end{tabular}

\# Eighteen patients with significant ST-segment depression in both tests were evaluated. \#\# $\mathrm{p}<0.01$ vs before treadmill exercise or dipyridamole infusion.

Abbreviations : $\mathrm{SBP}=$ systolic blood pressure; $\mathrm{HR}=$ heart rate; $\mathrm{PRP}=$ pressure rate product ; $\mathrm{NS}=$ not significant $; \mathrm{SD}=$ standard deviation

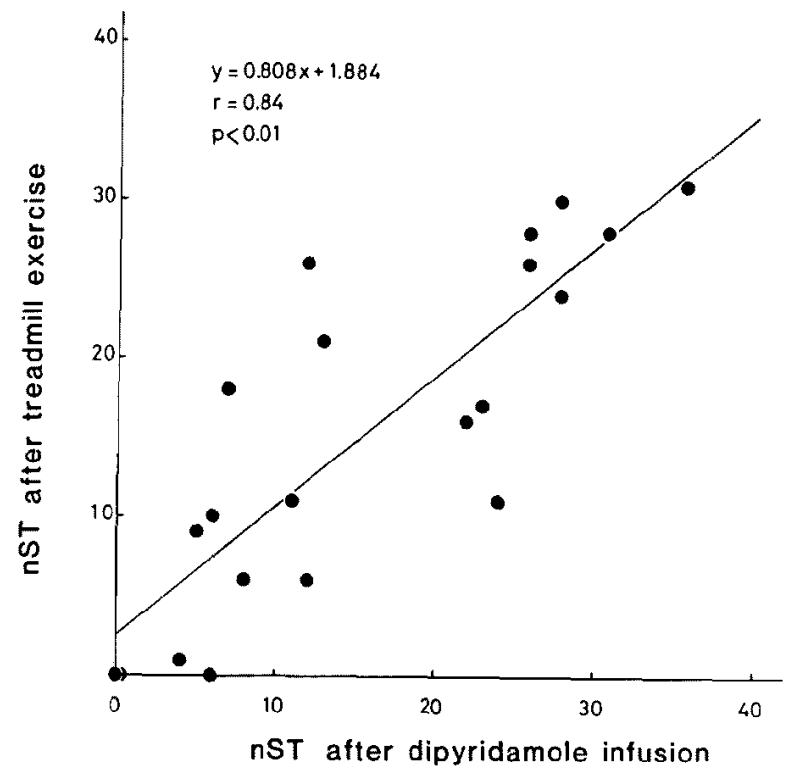

Fig. 2. Relationship between nST after treadmill exercise and $\mathrm{nST}$ after dipyridamole infusion. There was a good correlation between them $(\mathrm{r}=0.84)$.

Changes in heart rate, blood pressure and pressure-rate product

The summary of changes in heart rate, systolic blood pressure and pressure-rate product is shown in Table II.

In the treadmill test, heart rate, systolic blood pressure and pressure-rate 


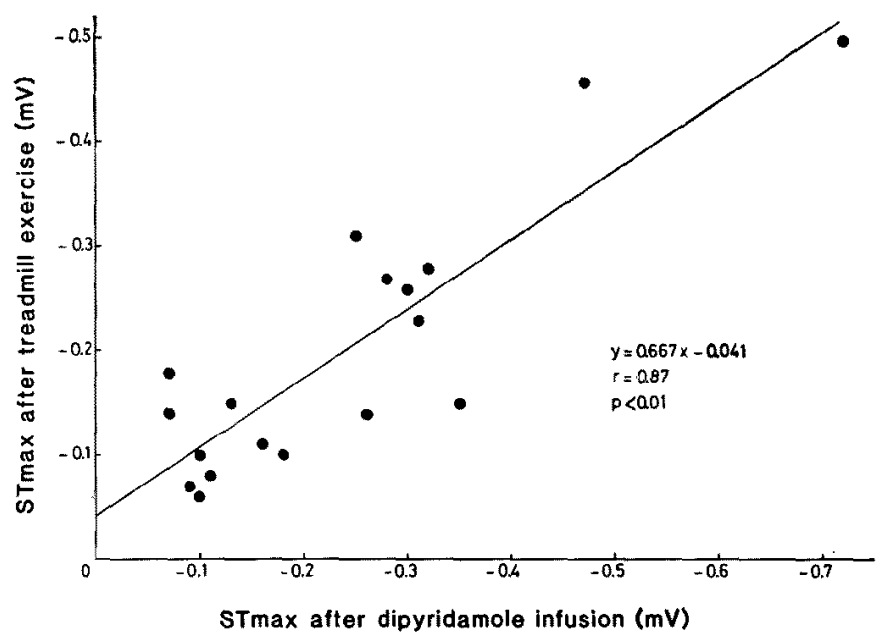

Fig. 3. Relationship between STmax after treadmill exercise and STmax after dipyridamole infusion. There was a good correlation between them $(r=0.87)$.

product all increased significantly $(\mathrm{p}<0.01)$. In the dipyridamole test, heart rate and pressure-rate product increased significantly $(\mathrm{p}<0.01)$, but systolic blood pressure did not change significantly. Before dipyridamole infusion systolic blood pressure tended to be higher and heart rate was significantly $(p<0.01)$ lower than those before treadmill excrcisc. These differences may have been due to the difference in position (dipyridamole test, supine; treadmill test, standing). However, there was no significant difference in pressurerate product between before dipyridamole infusion and before treadmill exercise. Heart rate, systolic blood pressure and pressure-rate product after dipyridamole infusion were all significantly lower than those after treadmill exercise $(p<0.01)$. The increases in mean heart rate and mean pressurerate product after treadmill exercise were $+60.6 \%$ and $+88.8 \%$, respectively, while the increases in mean heart rate and mean pressure-rate product after dipyridamole infusion were $+21.5 \%$ and $+21.5 \%$, respectively.

\section{Discussion}

\section{Comparison of electrocardiographic changes}

This study demonstrated that intravenous administration of $0.568 \mathrm{mg} / \mathrm{kg}$ dipyridamole for $4 \mathrm{~min}$ was as effective as submaximal treadmill exercise in producing ischemic ST-segment depression in patients with coronary artery disease. 
We employed as the criterion of significant ST-depression $0.05 \mathrm{mV}$ or greater horizontal or downsloping ST-depression. For the screening of coronary artery disease, ST-depression of $0.1 \mathrm{mV}$ is widely used to indicate a positive finding. However, the purpose of this study was to compare the spatial distribution pattern of ST-segment depression induced by dipyridamole infusion and treadmill exercise in patients with known coronary artery disease. In the presence of significant coronary artery narrowing, we considered that ST-depression of $0.05 \mathrm{mV}$ was sufficient when it was horizontal or downsloping.

We used three indices, nST, STmax and the site of STmax, to evaluate the body surface distribution pattern of ST-segment depression quantitatively, and showed that there was a close similarity in the spatial distribution of STsegment depression after dipyridamole infusion and after treadmill exercise in individual patients. It is generally believed that transient ST-segment depression associated with angina in patients with coronary artery disease is a reflection of subendocardial ischemia of the left ventricle. Our observations indicated that intravenously administered dipyridamole produced subendocardial ischemia of the same quality as did treadmill exercise. In each patient, the location and size of the ischemic myocardium were similar in the two tests.

\section{Mechanisms of dipyridamole-induced myocardial ischemia}

Although the same degree of ST-segment depression was evoked, the increase in pressure-rate product, which correlates well with myocardial oxygen consumption, ${ }^{25), 26)}$ was only $+21.5 \%$ after dipyridamole infusion, while it was $+88.8 \%$ after treadmill exercise. Thus, increased cardiac oxygen consumption does not seem to play a major role in the production of myocardial ischemia after dipyridamole infusion. Decreased blood pressure resulting in a decrease in coronary perfusion pressure has also been suggested as a possible cause of myocardial ischemia. ${ }^{15)}$ However, in our study population, systolic blood pressure did not change significantly after dipyridamole infusion.

A likely mechanism for dipyridamole-induced myocardial ischemia is that maximal vasodilation of small arteries associated with coronary stenosis may result in a reduction of subendocardial flow related to a coronary steal phenomenon or to decreased perfusion pressure. ${ }^{12-14), 16), 17)}$ First, coronary vasodilation may occur selectively in small arteries supplied by normal vessels, because vascular resistance in regions supplied by stenotic vessels is probably minimal due to the process of ischemia per se. ${ }^{271}$ Thus, coronary vasodilation may provoke a stealing of blood flow from zones supplicd by stenotic 
vessels to normal areas. Second, with coronary vasodilation, coronary flow and pressure gradient increase across the stenosis, distal coronary perfusion pressure decreases and the subendocardium may become underperfused.2,28)-30;

\section{Comparison with previous studies}

Dipyridamole-induced ST-segment depression occurred more frequently in our study $(19 / 21,90 \%)$ than in previous studies which reported that STscgment depression was less frequent after dipyridamole than after exercise testing. ${ }^{2), 31,5)-9), 151,18), 19)}$ Feldman et al14) reported that none of 13 patients had ST-segment depression after dipyridamole infusion, although 11 of them had ST-segment depression during exercise testing. Albro et al ${ }^{3)}$ also noted that only 2 of 51 patients with coronary stenosis $\geq 50 \%$ developed ST-segment depression after dipyridamole.

Several explanations should be considered for this discrepancy. First, our study population had relatively severe coronary artery disease as compared with those in the others studies. Eighteen of the 21 patients studied had two or three vessel disease. However, this may not be the major reason, because all 3 patients with one vessel disease showed ST-segment depression after dipyridamole (Cases 19-21).

Second, the post-exercise mapping data were recorded not immediately after, but at $1.5 \mathrm{~min}$ after the cessation of exercise. Thus, we may have underestimated the size and the magnitude of ST-segment depression in the treadmill test. However, this factor would not explain the higher incidence of ST-segment depression after dipyridamole infusion in the present study.

Third, drug therapy may affect dipyridamole-induced myocardial ischemia. In the present study, all medications were withheld for at least 24 hours before dipyridamole infusion. However, some studies ${ }^{6), 8), 14)}$ included patients who were taking cardiovascular drugs and some ${ }^{2,3), 5), 71,15)}$ did not mention whether cardiovascular medications were discontinued or not. Tavazzi et $a^{18)}$ performed dipyridamole infusion testing after all medications except sublingual nitroglycerin were discontinued for at least 12 hours and reported that $26(74 \%)$ of 35 patients with effort angina showed ST-segment changes after dipyridamole infusion. To determine the effect of drug therapy on dipyridamole-induced myocardial ischemia, we again performed dipyridamole infusion testing with premedication in 12 patients who developed ST-segment depression during the first test. After oral administration of nitrates $(n=4)$ or diltiazem $(n=8)$, ST-segment depression following dipyridamole infusion was completely suppressed in 11 of the 12 patients. This result indicated that dipyridamole-induced ST-segment depression, unlike myocardial perfusion imaging using dipyridamole, ${ }^{8)}$ was easily inhibited by medical treat- 
ment. Therefore, we think the lower incidence of ST-segment depression in other studies may be explained, at least in part, by the influence of cardiovascular medications.

\section{Clinical implications}

We demonstrated in the present study that there was a close similarity in the spatial distribution pattern of ST-segment depression after dipyridamole infusion and after treadmill exercise in patients with known coronary artery disease, although these electrocardiographic changes may be caused by different mechanisms. Therefore, dipyridamole electrocardiography may be used as an alternative test to exercise electrocardiography for the diagnosis of coronary artery disease. Since exercise is not required, this test may be of great value in patients who cannot achieve adequate exercise. Further studies should be conducted with a larger number of unselected patients to further define the clinical usefulness of this test.

\section{REFERENGES}

1. Gould KL: Noninvasive assessment of coronary stenoses by myocardial perfusion imaging during pharmacologic coronary vasodilatation. 1. Physiologic basis and experimental validation. Am J Cardiol 41:267, 1978

2. Gould KL, Westcott RJ, Albro PC, Hamilton GW: Noninvasive assessment of coronary stenoses by myocardial imaging during pharmacologic coronary vasodilatation. 2. Clinical methodology and feasibility. Am J Cardiol 41: 279, 1978

3. Albro PC, Gould KL, Westcott RJ, Hamilton GW, Ritchie JL, Williams DL: Noninvasive assessment of coronary stenoses by myocardial imaging during pharmacologic coronary vasodilatation. 3. Glinical trial. Am J Cardiol 42: 751, 1978

4. Gould KL: Assessment of coronary stenoses with myocardial perfusion imaging during pharmacologic coronary vasodilatation. 4. Limits of detection of stenosis with idealized experimental cross-sectional myocardial imaging. Am J Cardiol 42: 761, 1978

5. Narita M, Kurihara $T$, Usami $M$ : Noninvasive detection of coronary artery disease by myocardial imaging with thallium-201. The significance of pharmacologic interventions. Jpn Circ J 45: 127, 1981

6. Francisco DA, Collins SM, Go RT, Ehrhardt JC, Van Kirk OC, Marcus ML: Tomographic thallium-201 myocardial perfusion scintigrams after maximal coronary artery vasodilation with intravenous dipyridamole. Comparison of qualitative and quantitative approaches. Circulation 66: 370, 1982

7. Josephson MA, Brown BG, Hecht HS, Hopkins J, Pierce CD, Petersen RB: Noninvasive detection and localization of coronary stenoses in patients. Comparison of resting dipyridamole and cxercise thallium-201 myocardial perfusion imaging. Am Heart J 103: 1008, 1982

8. Leppo J, Boucher CA, Okada RD, Newell JB, Strauss HW, Pohost GM: Serial thallium-201 myocardial imaging after dipyridamole infusion. Diagnostic utility in detecting coronary stenoses and relationship to regional wall motion. Circulation 66:649, 1982

9. Terada $\mathrm{Y}$, Sugimoto T, Uraoka T, Yokawa S, Iuchi K, Akiyama M, Jinbo M, Futatsuya R, Seto H: Significance of dipyridamole-loading test in ischemic heart disease. Heart 15: 162, 1983 (in Japanese) 
10. Fam WM, McGregor M: Effect of coronary vasodilator drugs on retrograde flow in areas of chronic myocardial ischemia. Circ Res 15: 335, 1964

11. Nakamura M, Nakagaki O, Nose Y, Fukuyama T, Kikuchi Y: Effects of nitroglycerin and dipyridamole on regional myocardial blood flow. Basic Res Cardiol 73: 482, 1978

12. Becker LC: Conditions for vasodilator-induced coronary steal in experimental myocardial ischemia. Circulation 57: 1103, 1978

13. Gross GJ, Warltier DC: Coronary steal in four models of single or multiple vessel obstruction in dogs. Am J Cardiol 48: 84, 1981

14. Feldman RL, Nichols WW, Pepine GJ, Conti CR: Acute effect of intravenous dipyridamole on regional coronary hemodynamics and metabolism. Circulation 64: 333, 1981

15. Ando J, Yasuda H, Kobayashi T, Miyamoto A, Kanamori K, Murakami R, Matsumura N: Conditions for " coronary steal " caused by coronary vasodilation in man. Jpn Heart J 23: 79,1982

16. Beller GA, Holzgrefe HH, Watson DD: Intrinsic washout rates of thallium-201 in normal and ischemic myocardium after dipyridamole-induced vasodilator. Girculation 71: 378, 1985

17. Beller GA, Holzgrefe HH, Watson DD: Effects of dipyridamole-induced vasodilation on myocardial uptake and clearance kinetics of thallium-201. Circulation 68: 1328, 1983

18. Tavazzi L, Previtali M, Salerno JA, Chimienti M, Ray M, Medici A, Spechia G, Bobba P: Dipyridamole test in angina pectoris. Diagnostic value and pathophysiological implications. Cardiology 69: 34, 1982

19. DeAmbroggi L, Barbieri P, DeBiase AM, Repetto S, Radice M: Assessment of diagnostic value of dipyridamole testing in angina pectoris. Clin Cardiol 5:269, 1982

20. Kubota I, Saito K, Watanabe Y, Tsuiki K, Yasui S: Treadmill exercise test using body surface mapping. A quantitative diagnostic method for coronary artery disease. Jpn Heart J 22: 871,1981

21. Kubota I, Watanabe Y, Harada M, Kaminishi T, Tsuiki K, Yasui S: Treadmill stress test using body surface mapping in coronary artery disease. The clinical significance of $\mathrm{ST}$ depression. Jpn Circ J 46: 8, 1982

22. Kubota I, Ikeda K, Ohyama T, Yamaki M, Kawashima S, Igarashi A, Tsuiki K, Yasui S: Body surface distributions of ST segment changes after exercise in effort angina pectoris without myocardial infarction. Am Heart J 110: 949, 1985

23. Afonso S: Inhibition of coronary vasodilating action of dipyridamole and adenosine by aminophylline in the dog. Circ Res 26: 743, 1970

24. Watanabe T, Toyama J, Toyoshima H, Oguri H, Ohno M, Ohta T, Okajima M, Naito Y, Yamada K: A practical microcomputer based mapping system for body surface, precordium, and epicardium. Comput Biomed Res 14: 341, 1981

25. Kitamura K, Jorgensen CR, Gobel FL, Taylor HL, Wang Y: Hemodynamic correlates of myocardial oxygen consumption during upright exercise. J Appl Physiol 32: 516, 1972

26. Gobel FL, Nordstrom LA, Nelson RR, Jorgensen CR, Wang Y: The rate-pressure product as an index of myocardial oxygen consumption during exercise in patients with angina pectoris. Circulation 57: 549,1978

27. Rubio R, Berne RM: Regulation of coronary blood flow. Progr Cardiovasc Dis 18: 105, 1975

28. Gould $\mathrm{KL}$, Lipscomb $\mathrm{K}$ : Effects of coronary stenoses on coronary flow reserve and resistance. Am J Cardiol 34: 48, 1974

29. Lipscomb K, Gould KL: Mechanism of the effect of coronary artery stenosis on coronary flow in the dog. Am Heart J 89:60, 1975

30. Gould KL, Lipscomb K, Calvert C: Compensatory changes of the distal coronary vascular bed during progressive coronary constriction. Girculation 51: 1085, 1975 